\title{
Investigating the in vitro and in vivo nematicidal performance of structurally related macrolides against the root-knot nematode, Meloidogyne incognita
}

\author{
M.A. Radwan ${ }^{1 *}$, A.S.A. Saad ${ }^{2}$, H.A. Mesbah², H.S. Ibrahim ${ }^{3}$ and M.S. Khalil ${ }^{3}$
}

Summary Avermectins and spinosyns are structurally related natural products of microbial origin and belong to a new family of macrolides which are active against a vast array of invertebrate pests. In the present study, the effects of four members of macrolides; abamectin (ABM), emamectin benzoate (EMB), spinosad (SPI) and spinetoram (SPIT), on Meloidogyne incognita were investigated under in vitro and in vivo conditions. All compounds reduced egg hatching and led to high mortality of the nematode second-stage juveniles $\left(\mathrm{J}_{2}\right)$. ABM showed the maximum rate of egg hatching inhibition and $\mathrm{J}_{2}$ mortality while SPIT recorded the minimum. All treatments reduced the number of galls, egg masses, eggs/egg mass in roots and $J_{2}$ in the soil when compared to the control. Based on the 10 folds of the $24 \mathrm{~h}-\mathrm{LC}_{50}$ values of $\mathrm{J}_{2}$ mortality in vitro, $\mathrm{EMB}$ and $\mathrm{ABM}$ exhibited higher percent reduction in galls (79.68 and $71.45 \%)$, egg masses (75.19 and $70.54 \%)$, eggs/ egg mass (60.49 and $40.91 \%)$ and $\mathrm{J}_{2}$ in the soil (90.31 and $86.54 \%$ ), respectively, compared to SPI and SPIT. Significant increase in tomato shoot height occurred in all biopesticides ( 10 folds) and SPIT ( 20 folds). SPI at 10 folds of the $24 \mathrm{~h}$ - LC 50 values of $\mathrm{J}_{2}$ mortality in vitro, significantly increased root length while ABM at 50 folds and SPIT at 20 folds decreased root length by $5.15 \%$ and $5.88 \%$, respectively, compared to the untreated inoculated plants. In all treatments, the dry shoot and root weights increased, compared to the untreated control. Our findings suggest that these macrolides have the ability to regulate nematode population densities and may be an alternative to classical nematicides.

Additional keywords: avermectins, biopesticides, macrolides, nematicidal activity, root-knot nematodes, spinosyns

\section{Introduction}

Tomato (Solanum lycopersicum L.) is an important and vastly grown vegetable in Egypt and worldwide. However, its growth, yield and economic productivity are significantly reduced by pests and diseases. Plant parasitic nematodes (PPNs) are found to be the most common and destructive pests causing estimated crop losses of US $\$ 118$ billion each year worldwide (Atkinson et al., 2012). Among PPNs, Meloidogyne spp., root-knot

\footnotetext{
1 Pesticide Chemistry and Technology Department Faculty of Agriculture, (El-Shatby), Alexandria University, Egypt.

2 Plant Protection Department, Faculty of Agriculture (Saba-Basha), Alexandria University, Egypt.

${ }^{3}$ Central Agricultural Pesticides Laboratory, Agricultural Research Center, Dokki -Giza, Egypt.

* Corresponding author: mohamedalymahmoud2020@ gmail.com
}

nematodes, are harmful agricultural pests causing huge damage around the world (Sikora and Fernandez, 2005).

For sustainable tomato production, effective management of PPNs especially root-knot nematodes is essential. Several approaches are used to minimise PPNs in the field, including synthetic nematicides, resistant plant cultivars, botanical pesticides, antagonistic microorganisms (e.g. fungi and bacteria), beneficial fungi (Mycorrhiza), organic amendments, soil solarization and plant extracts (Collange et al., 2011; D'Addabbo et al., 2011; Radwan et al., 2012; Saad et al., 2017). Farmers rely mainly on the application of synthetic nematicides rather than on other approaches. However, lately many of these chemicals are being withdrawn from the markets due to environmental health and safety concerns (Rich et al., 2004). This highlights the need for devel- 
oping environmentally safer, target-specific ways of controlling these parasites.

To date, there is an increasing interest towards the utilisation of microorganisms as biocontrol agents in sustainable agriculture as an alternative to synthetic pesticides for controlling various crop pests and diseases, as well as improving crop yield. These microorganisms produce a great variety of structurally unique bioactive secondary metabolites. For example, Actinomycetes, which are found in soil and aquatic habitats produce more than 10,000 such active compounds. Among the bacteria used as microbial antagonists, Actinobacteria, especially Streptomyces spp., display activity against PPN by generating nematicidal metabolites (Mishra et al., 1987; Sun et al., 2006) and chitinolytic enzymes (Barka et al., 2016).

Avermectins, a new class of 16 -membered macrocyclic lactones, have four pairs of homologue compounds, i.e. four major components $A 1_{a}, A 2_{a}, B 1_{a}$ and $B 2_{a}$, and four minor components $A 1_{b}, A 2_{b}, B 1_{b}$ and $B 2_{b}$. Avermectins have been isolated from the crude fermentation product of Streptomyces avermitilis (Faske and Starr, 2007), and proved to possess a broad spectrum of pesticidal effects such as insecticidal, acaricidal, nematicidal and anthelmintic activities (Jansson and Dybas, 1998).

$A B M$, a blend of avermectins $B 1_{a}(<80 \%)$ and $\mathrm{B}_{\mathrm{b}}(>20 \%)$ with identical biological and toxicological properties (Pitterna et al., 2009), has nematicidal effects against rootknot and other nematode genera against several crops (Faske and Starr, 2007; Saad et al., 2017). On the other hand, EMB, a second generation avermectin derivative, is being developed for control of insect pests on different vegetable crops worldwide (Jansson and Dybas, 1998). It is structurally related to ABM having higher insecticidal action than ABM. It is also effective against root-knot nematodes (Rehman et al., 2009).

Spinosyns are novel macrolides, natural metabolites produced under aerial fermentation conditions by the soil actinomycete Saccharopolyspora spinosa. This Gram-positive bacterium produces SPI, a natural pesticide which is a mixture of spinosyn $A$ and spinosyn $D$ (85:15), that was reported to be an effective pest control agent with low toxicity to humans and the environment (Sparks et al., 1996).

SPI is toxicologically classified by the U.S. Environmental Protection Agency as a reduced risk material. SPIT is an analogue to SPI that belongs to spinosyns and it is a mixture of chemically modified spinosyns $J$ and $\mathrm{L}$. These molecules were found to have a wide spectrum of insect control potential on a variety of crops with high residual action (Huang et al., 2009).

Although the interest in avermectins, as one class of macrocyclic lactones (MLs) for nematicidal use, is increasing there is scarce information in the literature about the effectiveness of MLs compounds against rootknot nematodes. This encouraged us to continue investigating this group of chemicals for root-knot nematodes management. Therefore, the main goals of the present study were to assess the in vitro nematicidal potential of the structurally related macrolides; ABM, EMB, SPI and SPIT against Meloidogyne incognita. An in vivo pot trial was also undertaken to investigate their efficacy against the nematode on tomato under greenhouse conditions.

\section{Materials and Methods}

\section{Macrocyclic lactones and a standard ne- maticide}

ABM (Tervigo ${ }^{\circ} \% \mathrm{SC}$ ) and EMB (Proclaim ${ }^{\circ}$ $5 \%$ WG) were supplied by Syngenta, Egypt and SPI (Tracer $24 \%$ SC) and SPIT (Radient ${ }^{\circ}$ $12 \%$ SC) by Dow AgroSciences, Egypt and the standard nematicide oxamyl (Vydate24\% $\mathrm{SL}$ ) was supplied by E. I. du Pont de Nemours \& Company Inc. was used for comparison.

\section{Root-knot nematode inocula}

A single egg mass was excised from the roots of an infested eggplant (Solanum melongena cv. Black Beauty) and a pure culture of the root knot nematode isolate was propagated on the roots of tomato (S. Iycopersicum 
cv. Golden Stone) under greenhouse conditions. The population was eventually identified as Meloidogyne incognita, according to Taylor and Nelscher (1974) using perineal patterns. During the course of this study, eggs were being extracted from infected roots with sodium hypochlorite $(\mathrm{NaOCl})$ according to Hussey and Barker (1973) and second stage juveniles $\left(\mathrm{J}_{2}\right)$ obtained using the Baermann plate technique (Ayoub, 1980).

\section{In vitro assays}

The assessment of the effect of ABM, EMB, SPI and SPIT on hatching and mortality of $M$. incognita $\mathrm{J}_{2}$ was carried out in vitro. Preliminary experiments were conducted to establish the effective range of concentrations of the chemicals.

\section{Hatching assays}

The concentrations of each chemical tested during this study were as follows: for ABM and EMB, 25, 50, 100, 200 and $400 \mathrm{mg} / \mathrm{l}$; for SPI, 250, 500, 1000, 2000 and $3000 \mathrm{mg} / \mathrm{l}$ and for SPIT, 250, 500, 1000, 1500 and 2000 $\mathrm{mg} / \mathrm{l}$. Vials (each one ca. $15 \mathrm{ml}$ ) containing distilled water served as control. Each treatment was replicated four times and each replicate involved approximately 1200 eggs. The numbers of $J_{2}$, hatched from eggs, were recorded at 3 and 7 days after application.

\section{Mortality assays}

The concentrations of each chemical tested during this study were as follows: for $A B M, 12.5,25,50,75$ and $100 \mathrm{mg} / \mathrm{l}$; for $\mathrm{EMB}$, 25, 50, 75, 100 and $200 \mathrm{mg} / \mathrm{l}$; for SPI, 250, 500, 1000, 1500 and $3000 \mathrm{mg} / \mathrm{l}$ and for SPIT, 250, 500, 1000, 1500 and $2000 \mathrm{mg} / \mathrm{l}$. Each treatment was replicated four times including distilled water as a control and each replicate involved $200 \mathrm{~J}_{2}$. The numbers of both dead and alive $\mathrm{J}_{2}$ were recorded after 24 and $48 \mathrm{~h}$ exposure and the mortality percentages was estimated.

\section{Pot assay}

The nematicidal performance of $A B M$, EMB, SPI and SPIT was tested on tomato plants infested with $M$. incognita. Pots with capacity of one kg soil were filled with autoclaved loamy sand soil. ABM and EMB were applied as a soil drench at the rate of 10 and 50 folds of their $L C_{50}$ 's values based on $J_{2}$ mortality test after $24 \mathrm{~h}$ exposure, while SPI and SPIT were applied at the rate of 10 and 20 folds of their $L_{50}$ 's values after $24 \mathrm{~h}$ exposure. Oxamyl was used as a standard nematicide.

One one-month old tomato seedling $\mathrm{cv}$. HERMIS was transplanted in each pot, and three days later inoculated with 5000 eggs. Untreated uninoculated and untreated inoculated plants served as controls. All treatments were replicated five times and arranged in a complete randomized design on a bench in a greenhouse $\left(28 \pm 2{ }^{\circ} \mathrm{C}, 65 \pm 2 \mathrm{RH}\right.$ and 12: 12 $L: D$ photoperiod). During the course of the experiment, irrigation and fertilization were applied when appropriate. Fifty days after the inoculation, the plants were removed and washed free of soil. Shoot height and dry weight, root length and dry weight were measured and number of galls/root system, egg-masses/root system, eggs/egg-mass and $\mathrm{J}_{2} / 250 \mathrm{~g}$ soil were estimated. $\mathrm{J}_{2} \mathrm{~S}$ were extracted as previously mentioned and Phloxine $B$ was used to stain the roots to facilitate egg mass counting (Holbrook et al., 1983).

\section{Statistical analysis}

The statistical analysis of data was carried out using a computer Costat program (2005) version 6.303. Statistically significant differences between the means were compared using analysis of variance (ANOVA) with the least significant differences (LSD) and $P$-values at 0.05 probability. Hatching and $J_{2}$ mortality percentages were estimated using the Abbott formula (1925), and Probit analysis was used to calculate $\mathrm{LC}_{50}$ for each compound according to Finney (1971).

\section{Results}

Impact of test compounds on egg hatching and $J_{2}$ mortality of $M$. incognita under laboratory conditions

The egg hatching inhibition rate (\%) un- 
der laboratory conditions, due to exposure to the tested bioproducts after two time intervals is illustrated in Fig. (1). Hatching was inversely proportional to the concentration of the bioproducts. After 3 and 7 days exposure, the most effective compounds causing hatching reduction were $A B M(96.32$ and $85.41 \%$, respectively) and EMB (88.55\% and $71.23 \%$, respectively) at $400 \mathrm{mg} / \mathrm{l}$. At $2000 \mathrm{mg} / \mathrm{l}$, hatching inhibition was 73.83\% and $69.40 \%$ for SPI and $77.72 \%$ and $73.35 \%$ for SPIT (Fig. 1). LC 50 values on hatching inhibition after 3 and 7 days exposure were respectively, for ABM $24.61 \mathrm{mg} / \mathrm{l}$ and 46.89 $\mathrm{mg} / \mathrm{l}$, for EMB $47.97 \mathrm{mg} / \mathrm{l}$ and $83.09 \mathrm{mg} / \mathrm{l}$, for SPI $629.53 \mathrm{mg} / \mathrm{l}$ and $781.52 \mathrm{mg} / \mathrm{l}$ and for SPIT, $487.46 \mathrm{mg} / \mathrm{l}$ and $635.66 \mathrm{mg} / \mathrm{l}$ (Table 1 ).

$\mathrm{J}_{2}$ mortality increased by increasing compound concentration and exposure time, whereas no mortality occurred in the controls. After 24 and $48 \mathrm{~h}$ exposure, $\mathrm{J}_{2}$ mortality for $A B M$ at $100 \mathrm{mg} / \mathrm{l}$ was $73.01 \%$ and $86.00 \%$, respectively, and for EMB $51.43 \%$ and $63.08 \%$, respectively. SPI at $1500 \mathrm{mg} / \mathrm{l}$ caused a $45.22 \%$ and $50.66 \%$ mortality, while SPIT $32.86 \%$ and $42.03 \%$, respectively. This indicates that there is a marked increase in $\mathrm{J}_{2}$ mortality caused by ABM over EMB and by SPI over SPIT (Fig. 2). Probit analysis of these results indicates that, after $24 \mathrm{~h}$ exposure, $A B M$ was the most toxic compound against $\mathrm{J}_{2}\left(\mathrm{LC}_{50}=36.64 \mathrm{mg} / \mathrm{ml}\right)$ followed by $\mathrm{EMB}$, SPI and SPIT. LC $_{50}$ values after $48 \mathrm{~h}$ exposure were $22.89,79.03,1611.27$ and 2355.52 $\mathrm{mg} / \mathrm{l}$ for ABM, EMB, SPI and SPIT, respectively. In general, these compounds could be arranged according to their effectiveness on $\mathrm{J}_{2}$ mortality as follow: ABM > EMB > SPI > SPIT (Table 1).

\section{Effect of test compounds against $M$. in- cognita at pot assay}

All treatments showed differential nematicidal properties when compared to the untreated inoculated control. Gall formation was significantly suppressed by EMB, ABM, SPI and SPIT with reductions of 71.65, 69.46, 64.54 and $64.01 \%$, respectively. However, no significant differences were observed between $A B M$ and EMB and between SPI and
SPIT (Table 2). Except for EMB, no significant differences were observed between the lower and the higher rates of ABM, SPI and SPIT. The same trend was exhibited with respect to egg masses/root system. EMB was the most effective followed by ABM, SPI and SPIT, reducing egg masses by $76.28,74.57$, 56.20 and $51.24 \%$, respectively. No significant differences were detected between the lower and higher rates of all treatments. With respect to the number of eggs/egg mass, EMB, SPI, ABM and SPIT recorded reductions of $61.71,54.08,52.34$ and $45.61 \%$, respectively. The application of EMB, ABM, SPI and SPIT suppressed population density in soil by $91.82,89.26,74.33$ and $72.64 \%$, respectively, compared to the control. No significant differences were observed between the lower and the higher rates of all applied treatments (Table 2).

The effect of ABM, EMB, SPI and SPIT as a soil drench on the shoots and roots of the tomato seedlings is shown in Table 3 . Shoot height increased in all the treated plants by $23.35 \%$ to $48.24 \%$. The maximum increase was observed in plants treated with SPIT, followed by SPI, EMB and ABM. No significant differences were observed between the lower and the higher rates of all treatments. Noticeable increases were also recorded in the mean root length of plants treated with SPI, SPIT and EMB, i.e. $19.85 \%, 8.82 \%$ and $4.41 \%$, respectively, whereas $A B M$ reduced root length by $4.78 \%$. Noticeably, the higher rate of SPIT exhibited a root length reduction by $5.88 \%$ (Table 3 ).

Regarding dry shoot weight, data indicate an increase as compared to the control; the highest dry weight was observed with SPI (43.46\%), followed by SPIT (34.11\%), ABM (16.93\%) and EMB (16.54\%). ABM at the lower rate ( 10 folds) decreased dry shoot weight by $8.97 \%$. Plants treated with ABM showed significant differences between the lower and the higher rates, whereas no significant differences were found between the lower and the higher rates of EMB, SPI and SPIT (Table 4). All treatments recorded an increase in dry root weight over the untreated inoculated control. Such increase was min- 
imum (14.26\%) in plants treated with $A B M$, while treatment with SPI induced the maximum increase $(74.26 \%)$ over the control (Table 4).

\section{Discussion}

The present investigation revealed that the tested MLs compounds possess nematicidal properties against $M$. incognita under laboratory and greenhouse conditions with the following descending order $A B M>E M B$ $>$ SPI $>$ SPIT. The findings of the present in vitro studies are in conformity with previous studies in which ABM nematode toxicity was higher than that of EMB. ABM was more effective than $E M B$ on hatching inhibition and juveniles mortality of $M$. incognita in laboratory tests (Ullah et al., 2015). ABM has been found more toxic than EMB with respect to the number of galls and egg masses in roots, with 61.77 and $78.82 \%$, and 43.75 and $56.41 \%$ reductions, respectively (Shahid et al., 2009). $\mathrm{d}^{\prime}$ Errico et al. (2017) reported that Tervigo ${ }^{\circledR}$ (ABM 2\% SC) and two other formulations, CHA 2061-02 EW and CHA 2080 SC, showed a nematostatic activity against $M$. incognita $\mathrm{J}_{2}$ in vitro, where after exposure to these products, $J_{2}$ were immobilized and subsequently resumed mobility over time following a recovery test. AVM $B_{1}$ when used at 10 and 100 $\mathrm{mg} / \mathrm{l}$ completely inhibited egg hatchability of Meloidogyne arenaria Chitwood in vitro (Cayrol et al., 1993). Avicta ${ }^{\circledR}$ containing ABM reduced hatching and increased $M$. javanica $\mathrm{J}_{2}$ mortality in vitro. In addition to the nematostatic effect, Avicta ${ }^{\circledR}$ possessed a nematicidal effect (Almeida et al., 2017). However, while studying the toxicity of EMB and $A B M$ to $M$. incognita juveniles in the laboratory, Ding et al. (2009) reported that the toxicity of EMB was found higher than that of ABM, their $L_{50}$ being 0.1645 and $0.4532 \mathrm{mg} / \mathrm{l}$, respectively. Also, EMB was highly toxic to $M$. incognita juveniles with $\mathrm{LC}_{50}$ and $\mathrm{LC}_{90}$ values of 3.59 and $18.20 \mathrm{mg} / \mathrm{L}$ after $48 \mathrm{~h}$ of exposure, respectively (Cheng et al., 2015).

Indeed, avermectins have already been proven nematicidal and effective in reduc- ing nematode populations both in soil and the roots of infested plants. Regardless the method of application, our findings confirmed published reports in which ABM was effective against root-knot nematodes on cotton (Faske and Starr, 2007), tomato (Qiao et al, 2012; Ullah et al., 2015; Saad et al., 2017) and cucumber (Huang et al., 2014). Nursery bed soil drenching with EMB $1.9 \%$ WP at $285.0 \mathrm{~g}$ a.i./ha before or after sowing, induced high reduction of the $J_{2}$ population in the soil as well as of the number of females per g root (Das et al., 2014).

SPIT is often more potent, faster-acting, and longer-lasting than SPI as an insecticide (Sparks et al., 2008; Dripps et al., 2011). In the present study, spinosyn compounds displayed satisfactory results regarding the nematicidal activity against $M$. incognita, both under in vitro and in vivo conditions. However, their nematicidal efficacy was lower than that of the avermectin compounds. To our knowledge, the potency of spinosyn against PPNs has not been reported yet, except for the effect of SPI as a nematicide recorded by Khalil (2013) where Tracer $24 \%$ SC at 0.5 and $0.1 \%$ reduced $M$. incognita populations by 70.90 and $62.51 \%$, respectively.

The increase in plant growth parameters, such as shoot height, root length and dry weight of either shoots and roots suggests that the treatments tested during this study have a good potential nematicidal effect on the root knot nematode $M$. incogni$t a$, which can result in effective plant protection. The obtained results are consistent with the earlier report by Ding et al. (2009) that proved the effectiveness of EMB in improving plant growth of tomato. Such improvement in plant growth is possibly due to the reduction in PPN populations. Our findings are also in agreement with the data of Khalil (2012) and Saad et al. (2017), who found that ABM when applied against $M$. incognita infesting tomato plants, increased all plant growth parameters. Moreover, ABM enhanced cucumber plant vigor and fruit yield (Huang et al., 2014). However, Khalil (2013) found that SPI at $0.1 \%$ reduced the fresh weight of roots by $20.69 \%$ when ap- 


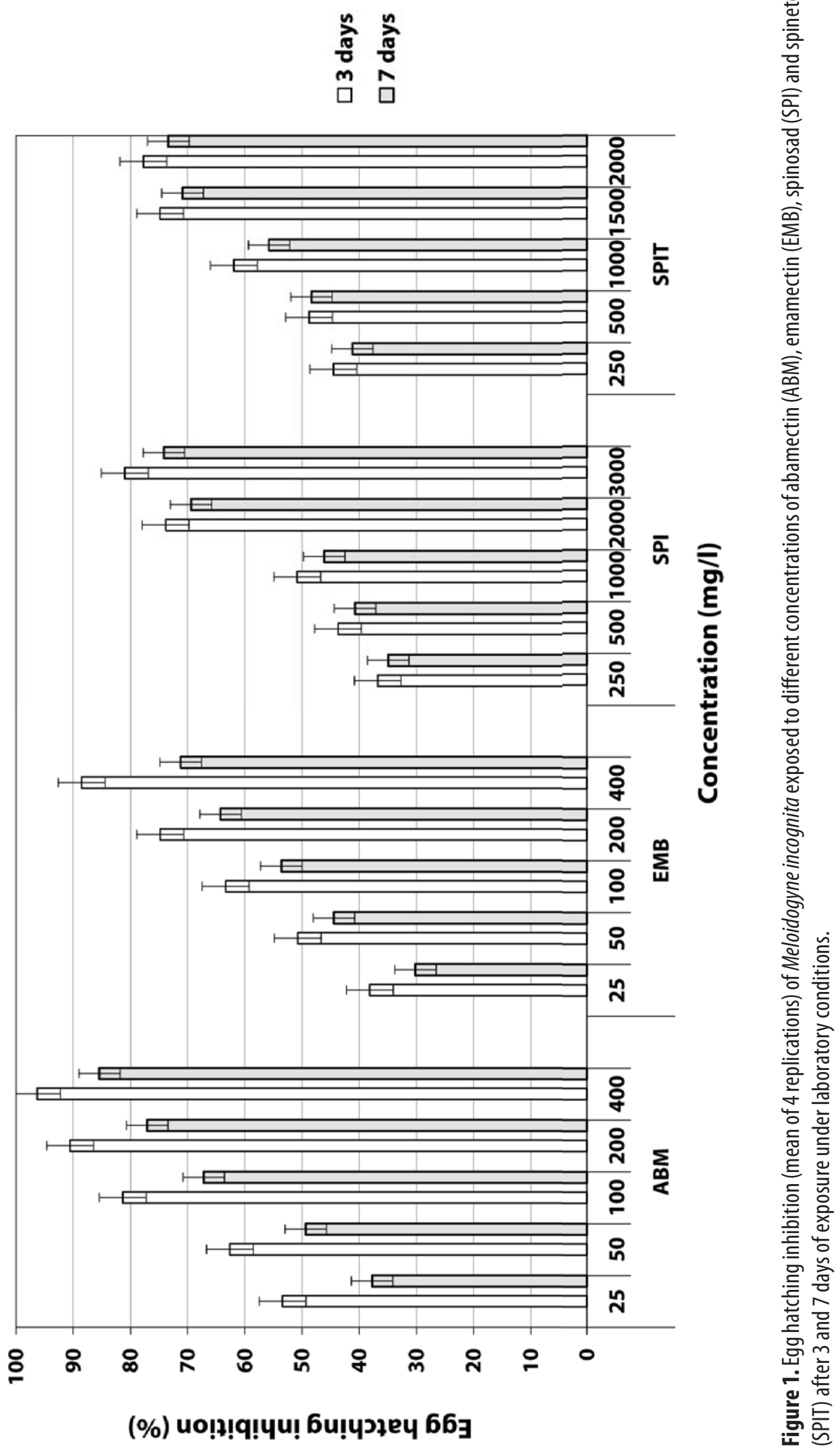




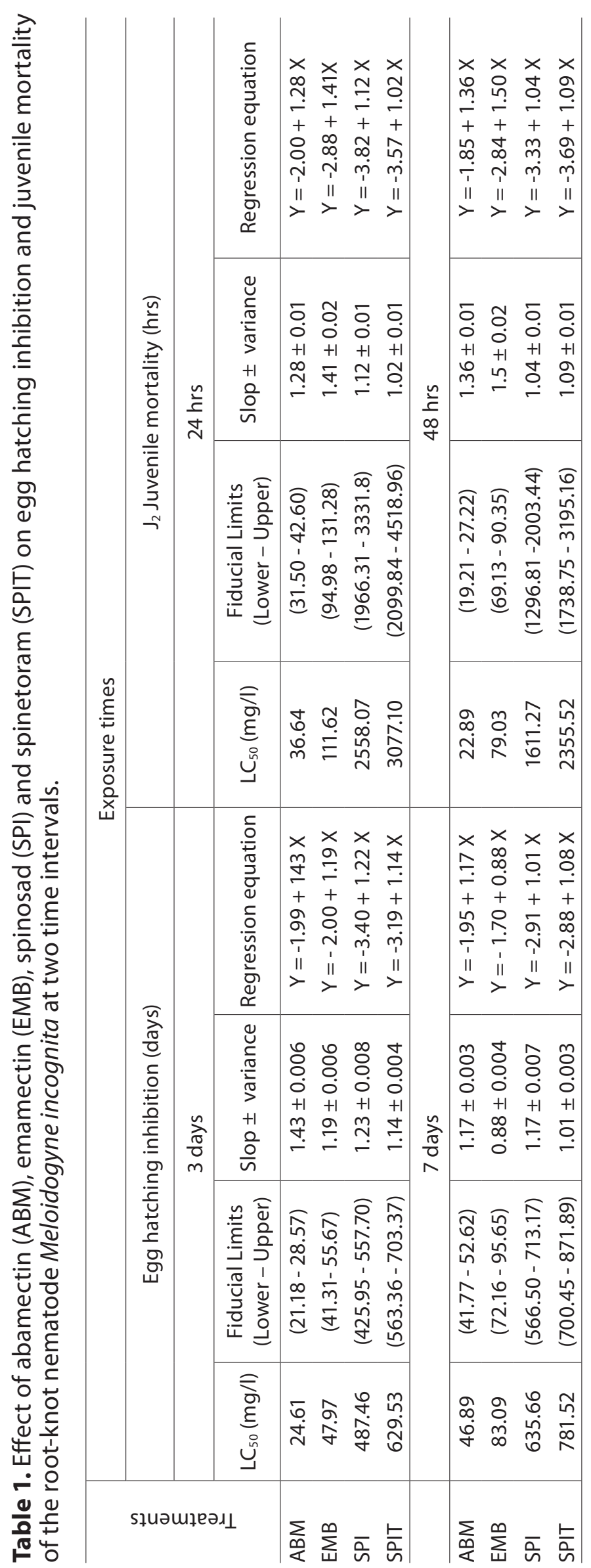




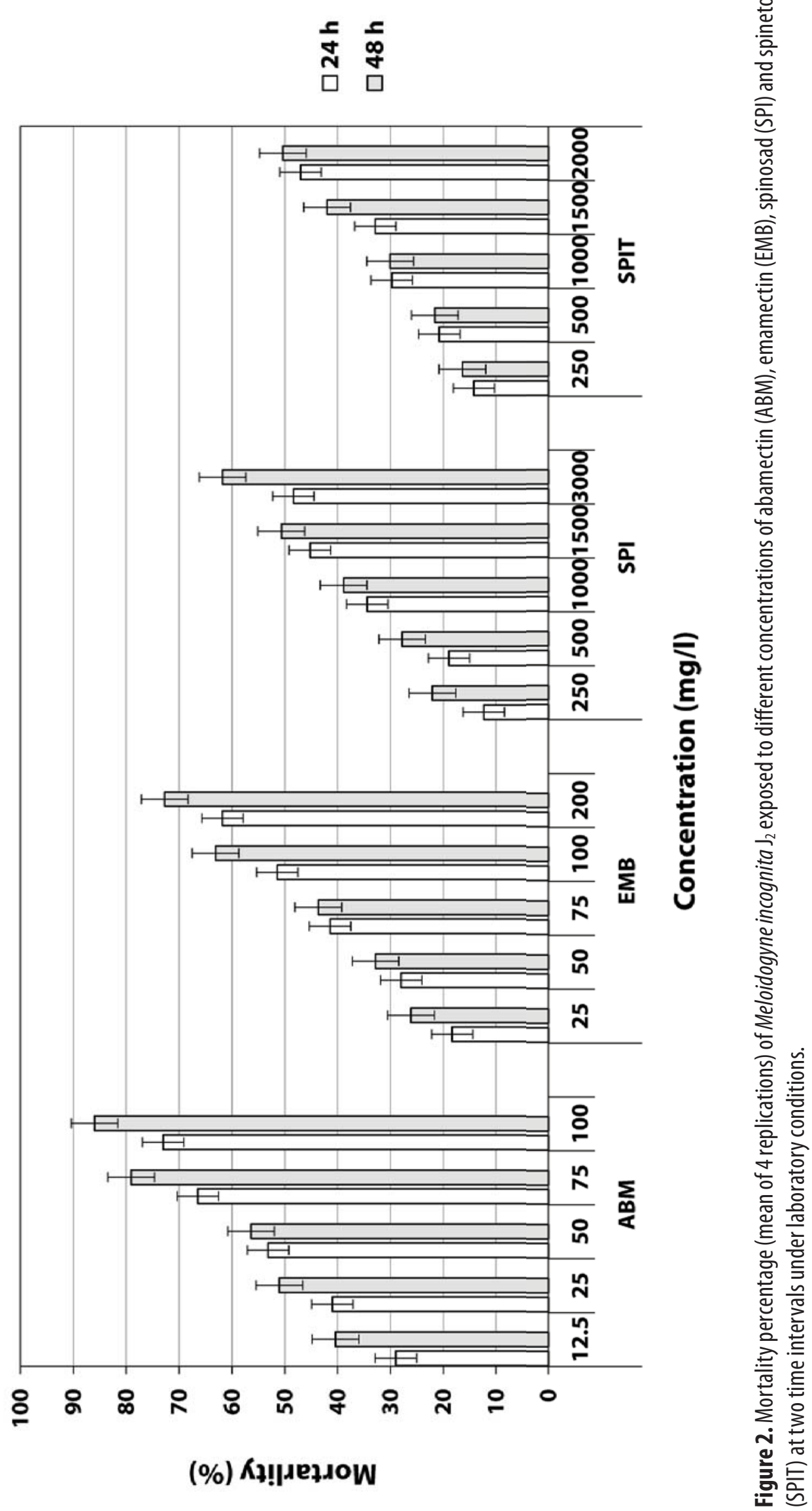




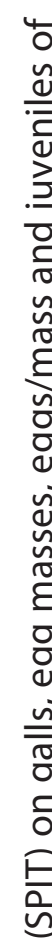

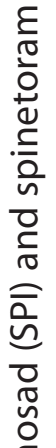

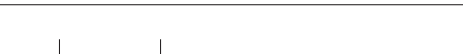

은

은 웅

क्षे

$\sum_{\Psi}^{\uplus}$

.

过

है

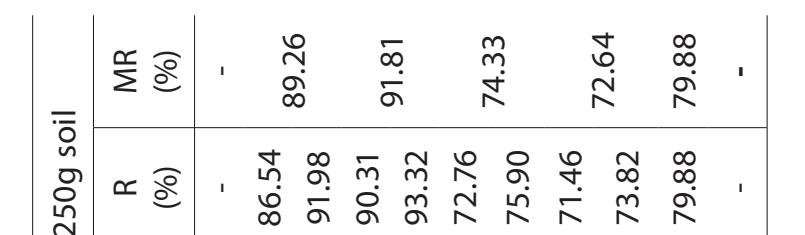

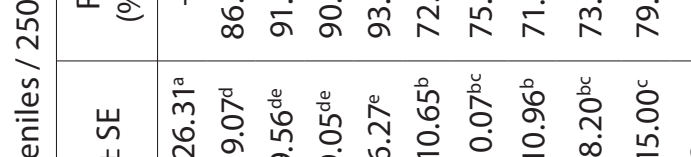

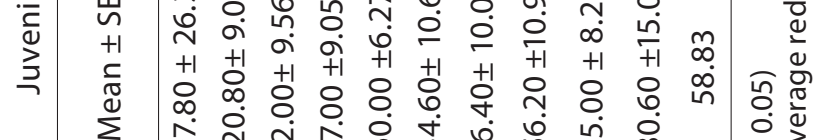

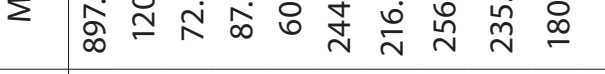

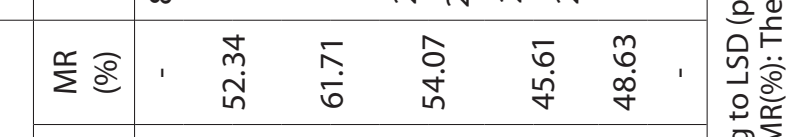

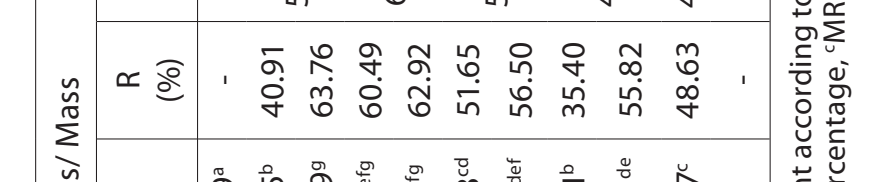

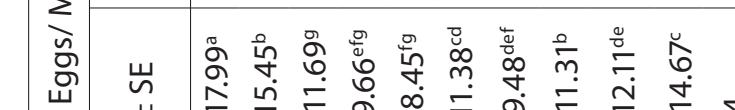

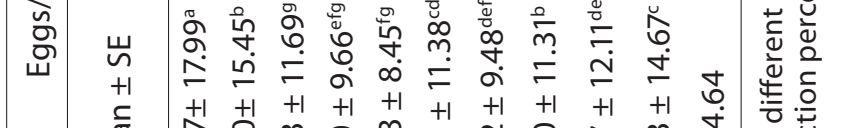

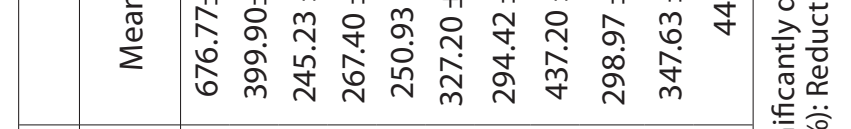

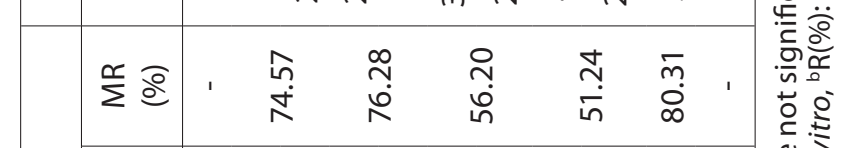

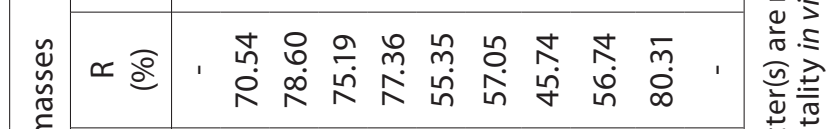

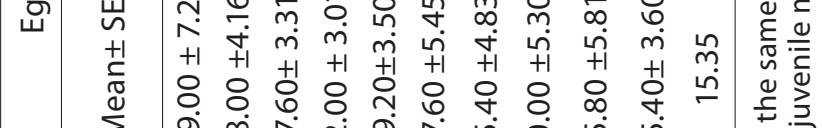

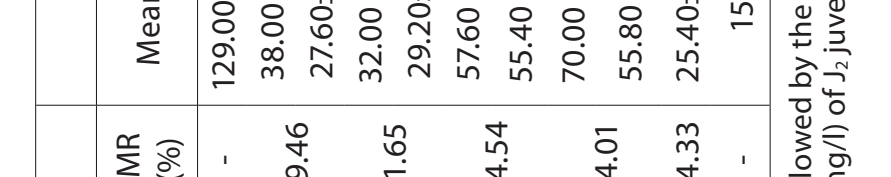

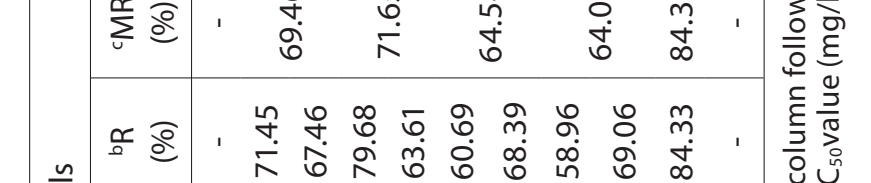

要

ত্ত

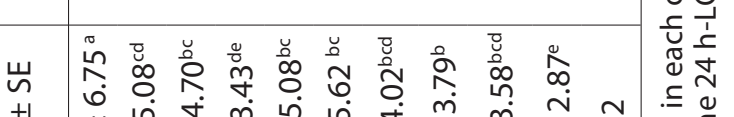

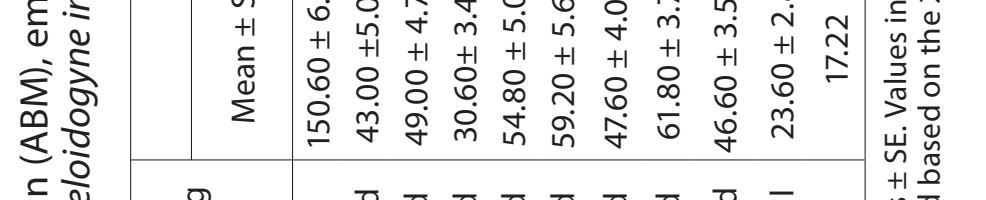

正

है $\frac{0}{0}$

蚛

苮

บ

屯ै

岃

눈

응 임

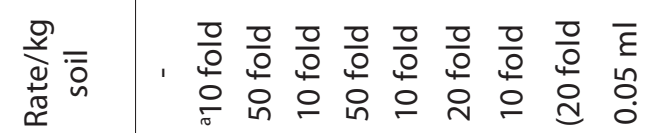

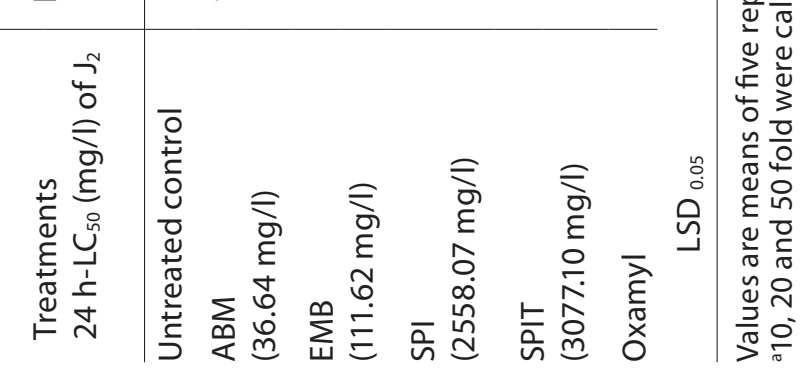




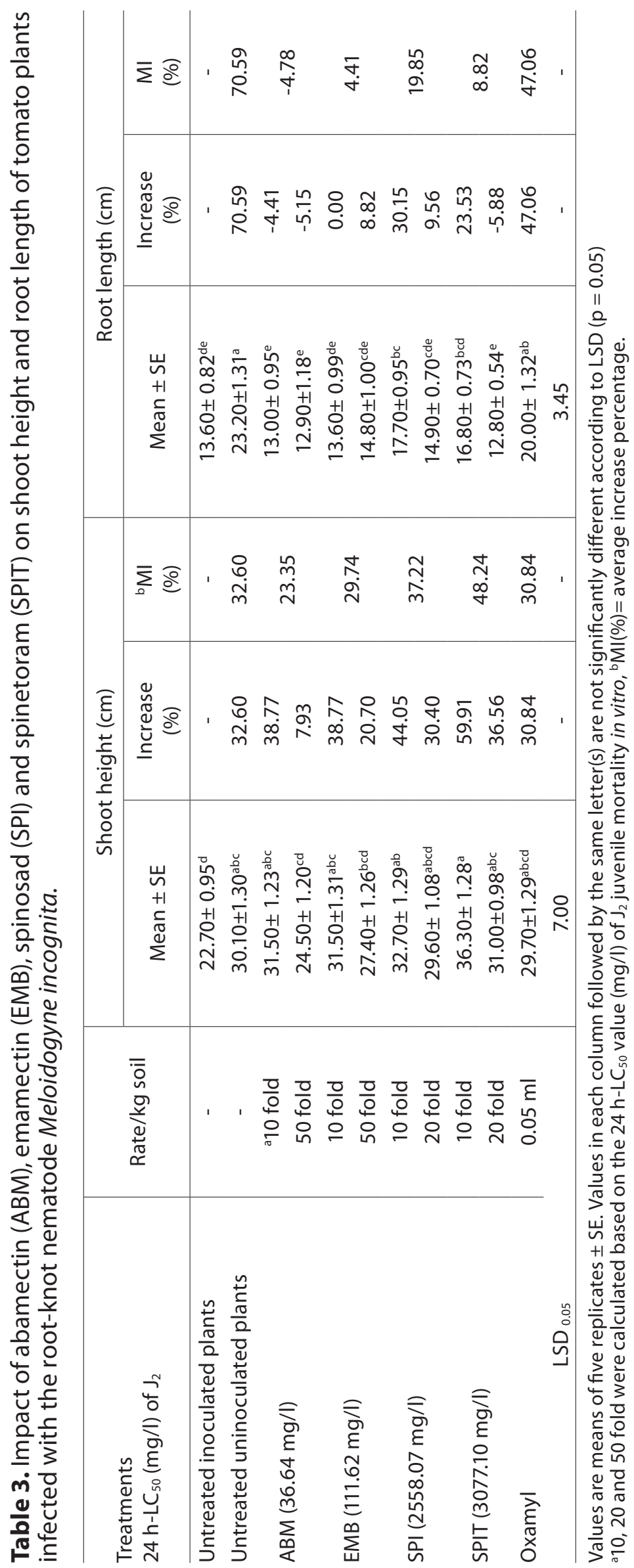




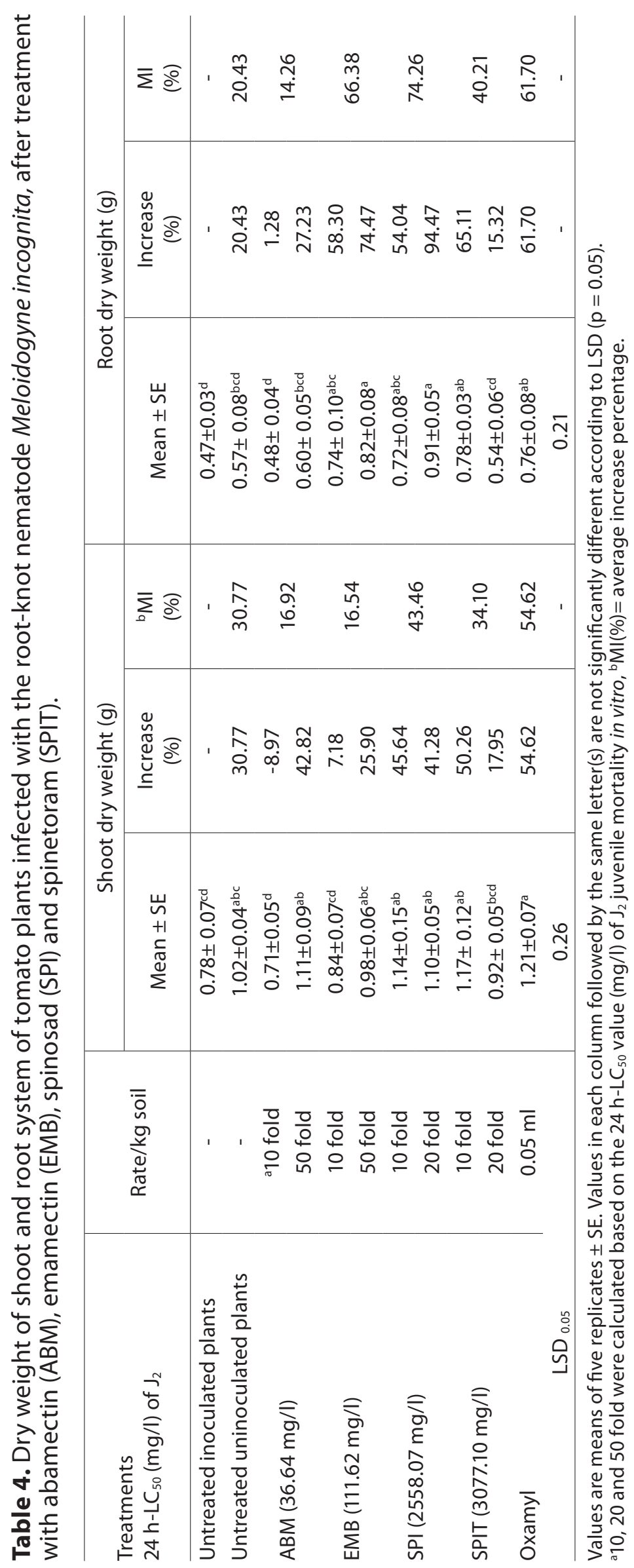


plied against $M$. incognita on tomatoes. The decrease in some plant growth parameters in the present study may be attributed to phytotoxicity.

Overall, the tested avermectins and spinosins can be considered as interesting alternative tools for the management of the root-knot nematode, $M$. incognita, being compounds with a good nematicidal potential, which have different mode of action to the available nematicides (Salgado, 1998; Bloomquist, 2003; Watson et al., 2010).

\section{Conclusions}

The current study provides evidence that the structurally related macrocyclic lactone compounds ABM, EMB, SPI and SPIT have a good potential to control the population of the root-knot nematode, $M$. incognita, by reducing hatching and increasing $J_{2}$ mortality in vitro. Also, soil drenching with these compounds significantly reduced the reproduction of M. incognita and consequently enhanced tomato growth characters. ABM and EMB as members of avermectins had greater efficacy on the $M$. incognita than SPI and SPIT as members of spinosyns. In general, the tested compounds are promising alternatives (bionematicides) to the classical nematicides for the control of root-knot nematodes in tomato production. Nevertheless, further research is required to assess the nematicidal properties of these compounds under field conditions. Furthermore, future research can extend to designing new controlled release formulations based on a nano-delivery system, which would enhance their efficacy and expand their use in the area of PPN management.

\section{Declaration of Conflicting Interests}

The author(s) declared no conflicts of interest with respect to the research, authorship, and/or publication of this article.

\section{Funding}

The author(s) received no financial support for the research, authorship, and/or publication of this article.

\section{Literature cited}

Abbott, W.S. 1925. A method of computing the effectiveness of an insecticide. Journal of Economic Entomology, 18: 265-267.

Almeida, A.A. de, Abe, V.H.F., Gonçalves, R.M., Balbi-Peña, M.I. and Santiago, D.C. 2017. Seed treatment for management of Meloidogyne javanica in soybean. Semina: Ciências Agrárias, Londrina, 38: 2995-3006.

Atkinson, H.J., Lilley, J.C. and Urwin, E.P. 2012. Strategies for transgenic nematode control in developed and developing world crops. Current Opinion Biotechnology 23: 251 -256.

Ayoub, S.M. 1980. Plant Nematology, an Agricultural Training Aid. California, USA: Nema Aid Publications.

Barka, E.A., Vatsa, P., Sanchez, L., Gaveau-Vaillant, N., Jacquard, C., Meier-Kolthoff, J.P., Klenk, H.P., Clément, C., Ouhdouch, Y.and van Wezel, G.P. 2016. Taxonomy, physiology, and natural products of actinobacteria. Microbiology and Molecular Biology Reviews. 80: 1-43.

Bloomquist, J. R. 2003. Chloride channels as tools for developing selective insecticides. Archives of Insect Biochemistry and Physiology, 54: 145-156.

Cayrol, J.C., Djian, C. and Frankowskj J.P. 1993. Efficacy of abamectin $\mathrm{BI}$ for the control of Meloidogyne arenaria. Fundamental and Applied Nematolology, 16: 239-246.

Cheng, X., Liu, X., Wang, H., Ji, X., Wang, K., Wei M. and Qiao, K. 2015. Effect of emamectin benzoate on root-knot nematodes and tomato yield. PLOS ONE, 10(10): e0141235. doi:10.1371/journal. pone.0141235

Collange, B., Navarrete, M., Peyre, G., Mateille, T. and Tchamitchian, M. 2011. Root knot nematode (Meloidogyne) management in vegetable crop production: the challenge of an agronomic system analysis. Crop Protection, 30: 1251-1262.

Costat software 2005. Microcomputer program analysis, CoHort software, Version 6.303, Monterey, CA, USA.

D’Addabbo, T., Papajova, I., Sasanelli, N., Radicci, V. and Renco, M. 2011. Suppression of root-knot nematodes in potting mixes amended with different composted biowastes. Helminthologia, 48: 278-287.

Das, A. K., Maji, T. B., Kadam, V. and Mukhopadhyay, A.K. 2014. Effect of nursery bed soil drenching with emamectin benzoate $1.9 \% \mathrm{WP}$, a novel avermectin derivative, towards eco-friendly management of root-knot nematodes in chilli. The Bioscan 9: 329-334.

d'Errico, G., Marra, R., Vinale, F., Landi, S., Roversi, P. F. 
and Woo, S.L. 2017. Nematicidal efficacy of new abamectin-based products used alone and in combination with indolebutyric acid against the root-knot nematode Meloidogyne incognita. Journal of Zoology,100: 95-101.

Ding, X.-F, Liang, R. and Wang, X.-J. 2009. Toxicity and control efficacy of emamectin benzoate to the root-knot nematode Meloidogyne incognita as well as its safety to tomato. Journal of Nanjing Agricultural University, 04.

Dripps, J.E., Boucher, R.E., Chloridis, A., Cleveland, C.B., De Amicism, C.V., Gomez, L.E., Paroonagian, D.L., Pavan, L.A., Sparks, T.C. and Watson, G.B. 2011. The spinosyn insecticides. In: LOPEZ, O. et al. (eds), Trends in Insect Control. Cambridge, UK: Royal Society of Chemistry, p. 163-212.

Faske, T.R. and Starr,J.L. 2007. Cotton root protection from plant-parasitic nematodes by abamectintreated seed. Journal of Nematology, 39: 27-30.

Finney, D.J. 1971. Probit Analysis $3^{\text {rd }}$ Edition, Cambridge, UK: Cambridge University Press.

Holbrook, C.C., Knauft, D.A. and Dickson, D.W. 1983. A technique for screening peanut for resistance to Meloidogyne arenaria. Plant Disease, 67: 957958.

Huang, K.X., Xia, L., Zhang, Y., Ding, X. and Zahn, J.A. 2009. Recent advances in the biochemistry of spinosyns. Applied Microbiology and Biotechnology, 82: 13-23.

Huang, W.K., Sun, J.H., Cui, J.K., Wang, G.F., Kong, L.A., Peng, H., Chen, S.L. and Peng, D.L. 2014. Efficacy evaluation of fungus Syncephalastrum racemosum and nematicide avermectin against the root-knot nematode Meloidogyne incognita on cucumber. PLOS ONE, 9(2): e89717.

Hussey, R.S. and Barker, K.R. 1973. A comparison of methods of collecting inocula on Meloidogyne spp., including a new technique. Plant Disease Report, 57: 1025-1028.

Jansson, R.K. and Dybas, R.A. 1998. Avermectins: Biochemical mode of action, biological activity and agricultural importance. In: ISHAAYA, I., DEGHEELE, D. (eds). Insecticides with Novel Modes of Action: Mechanisms and Application. New York: Springer-Verlag. p.152-167.

Khalil, M.S. 2012. A comparison study with alternative biorational agents to suppress the rootknot nematode populations and gall-formation in tomato plants. International Journal of Nematology, 22: 112-116.

Khalil, M.S. 2013. Nematicidal performance of two agrochemicals and spinosad on the root-knot nematode population. Canadian Journal of Plant Protection, 1: 177-181.

Mishra, S.K., Keller, J.E., Miller, J.R., Heisey, R.M, Nair, M.G. And Putnam, A.R. 1987. Insecticidal and nematicidal properties of microbial metabolites. Journal of Industrial Microbiology 2: 267-276.

Pitterna, T., Cassayre, J., Hüter, O.F., Jung, P.M. and
Maienfisch, P. 2009. New ventures in the chemistry of avermectins. Bioorganic \& Medicinal Chemistry, 17: 4085-4095.

Qiao, K., Liu, X., Wang, H., Xia, X., Ji, X. and Wang, K. 2012. Effect of abamectin on root-knot nematodes and tomato yield. Pest Management Science, 68: 853-857.

Radwan, M.A., Farrag, S.A.A., Abu-Elamayem, M.M. and Ahmed, N.S. 2012. Biological control of the root-knot nematode, Meloidogyne incognita on tomato using bioproducts of microbial origin. Applied Soil Ecology. 56: 58-62.

Rehman, A.U., Javed, N., Ahmad, R. and Shahid, M. 2009. Integration of bio-products and Pasteuria penetrans for the management of root-knot nematode over three crop cycles of tomato. Pakistan Journal of Nematology, 27: 325-336.

Rich, J.R., Dunn, R. and Noling, J. 2004. Nematicides: past and present uses. In: CHEN, ZX. et al. (eds.). Nematology: Advances and Perspectives, Vol 2. Nematode Management and Utilization. Oxfordshire, UK: CABI Publishing, p. 1041-1082.

Saad, A.S.A., Radwan, M.A., Mesbah, H.A., Ibrahim, H.S. and Khalil, M.S. 2017. Evaluation of some non-fumigant nematicides and the biocide avermactin for managing Meloidogyne incognita in tomatoes. Pakistan Journal of Nematology, 35: 85-92.

Salgado, V.L. 1998. Studies on the mode of action of spinosad: Insect symptoms and physiology correlates. Pesticide Biochemistry and Physiology, 60: 91-102.

Shahid, M., Rehman, A.U., Khan, S.H., Mahmood, K. and Khan, A.U. 2009. Management of root-knot nematode infecting brinjal by biopesticides, chemicals, organic amendments and bio-control agent. Pakistan Journal of Nematology, 27: 159- 166.

Sikora, R.A. and Fernandez, E. 2005. Nematode parasites of vegetables. In: LUC, M., et al. (eds.). Plant Parasitic Nematodes in Subtropical and Tropical Agriculture. Wallingford, UK: CABI Publishing, p. 319-392.

Sparks, T.C., Crouse, G.D., Dripps, J.E., Anzeveno, P., Gifford, J.M., DeAmicis, C.V. and Gifford, J. 2008. Neural network based QSAR and insecticide discovery: spinetoram. Journal of Computer-Aided Molecular Design, 22: 393-401.

Sparks, T.C., Kirst, H.A., Mynderse, J.S., Thompson, G.D., Turner, J.R., Jantz, M.B., Hertlein, L.L., Larson, P.J., Baker, M.C., Broughton, J.D., Busacca, L.C., Creemer, M.L., Huber, J.W., Martin, W.M., Nakatsukasa, WM., Paschal, J.W. and Worden, T.V. 1996. Chemistry and biology of the spinosyns: components of spinosad (Tracer), the first entry into Dow Elanco's naturalyte class of insect control products. In Proceedings, Beltwide Cotton Conference, Nashville, USA, 9-12, January, 1996, National Cotton Council of America, Memphis, p. 692-695. 
Sun, M.H., Gao, L., Shi, Y.X., Li, B.J. and Liu, X.Z. 2006. Fungi and actinomycetes associated with Meloidogyne spp. eggs and females in China and their biocontrol potential. Journal of Invertebrate Pathology,93: 22-28.

Taylor, D.P. and Nelscher, C. 1974. An improved technique for preparing perineal patterns of Meloidogyne spp. Nematology, 20: 268-269.

Ullah, Z., Javed, N., Khan, S.A., Haq, I.U. and Shakeel, Q. 2015. Efficacy of biopesticides for management of root knot nematode on tomato. International Journal of Vegetable Science, 21: 215222.
Watson, G.B., Chouinard, S.W., Cook, K.R., Geng, C., Gifford, J.M., Gustafson, G.D., Hasler, J.M., Larrinua, I.M., Letherer, T.J., Mitchell, J.C., Pak, W.L., Salgado V.L., Sparks, T.C. and Stilwell, G.E. 2010. A spinosyn-sensitive Drosophila melanogaster nicotinic acetylcholine receptor identified through chemically induced target site resistance, resistance gene identification, and heterologous expression. International Journal of Vegetable Science, 40: 376-384.

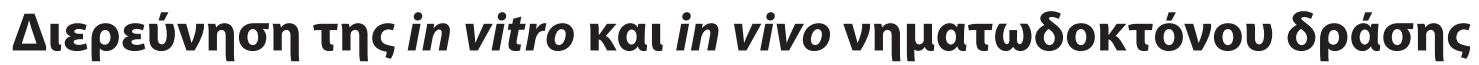

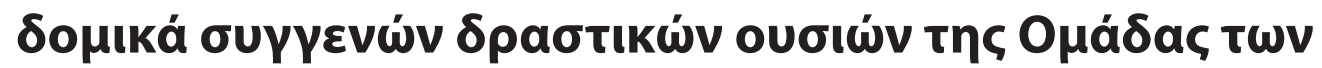

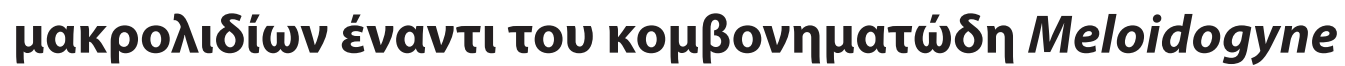 incognita
}

\author{
M.A. Radwan, A.S.A. Saad, H.A. Mesbah, H.S. Ibrahim kaı M.S. Khalil
}

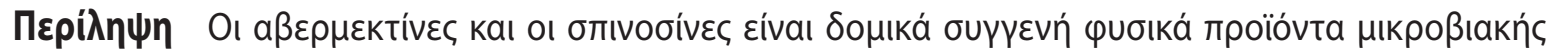

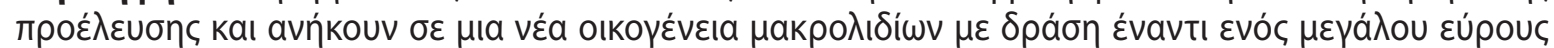

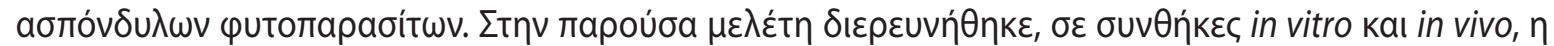

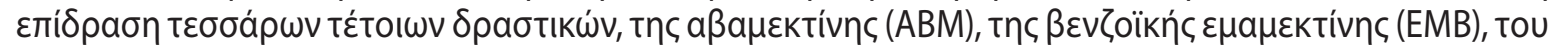

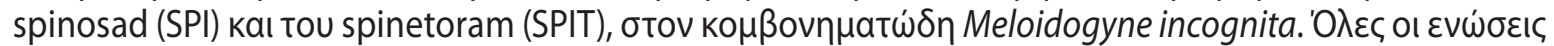

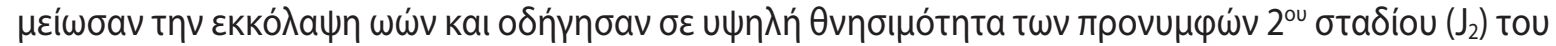

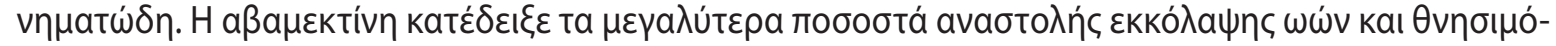

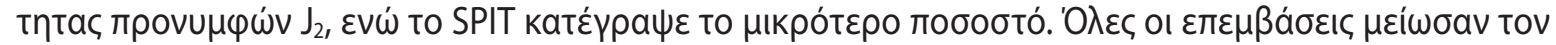

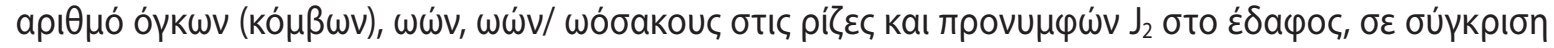

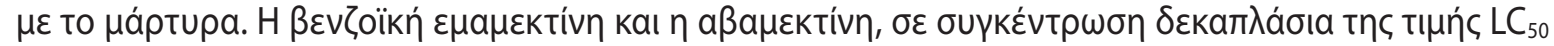

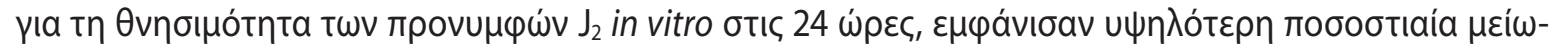

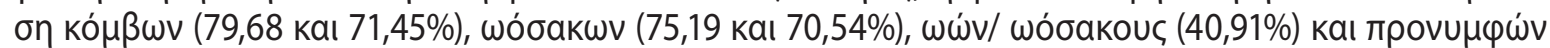

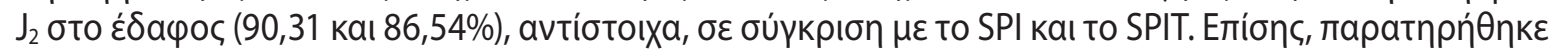

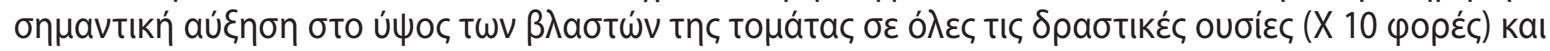

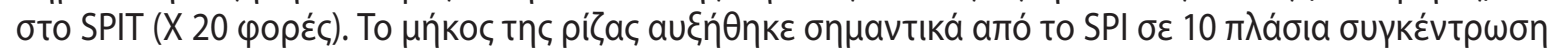

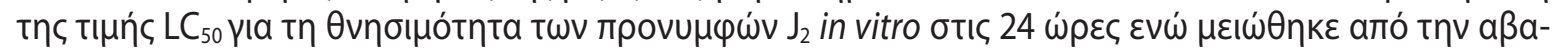

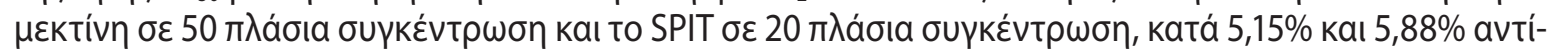

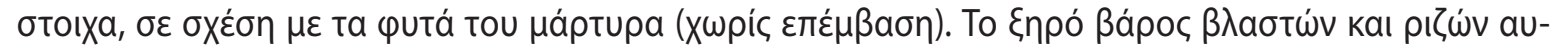

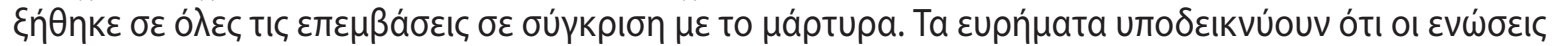

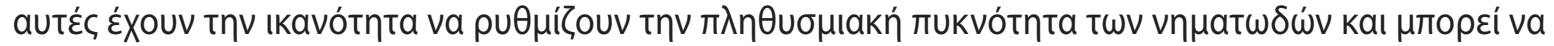

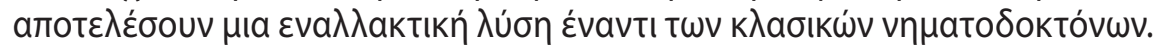

Hellenic Plant Protection Journal 12: 24-37, 2019 